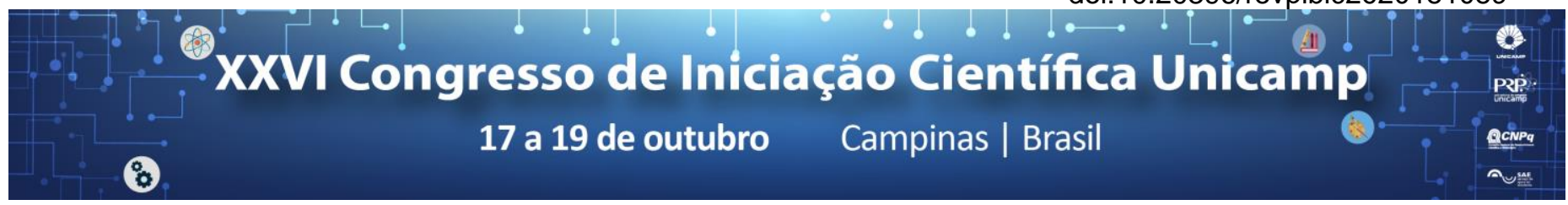

\title{
Simulação computacional de incêndios em edificações
}

\section{Natiele Bandeira da Silva*, Prof. Dr. Saulo José de Castro Almeida.}

\section{Resumo}

O presente trabalho tem por objetivo a análise da deflagração e propagação de incêndios em edificações utilizando a fluidodinâmica computacional por meio do software FDS (Fluid Dinamics Simulator). Para tanto, realizou-se um estudo de caso com o prédio do Departamento de Estruturas da Faculdade de Engenharia Civil Arquitetura e Urbanismo da Universidade Estadual de Campinas. De acordo com os resultados, a depender de fatores como evacuação e ventilação, um pequeno incêndio pode se mostrar danoso aos ocupantes da edificação investigada.

\section{Palavras-chave:}

Simulação computacional, Segurança contra Incêndio, FDS - Fire Dinamic Simulator.

\section{Introdução}

O estudo das edificações em situação de incêndio tem dentre seus objetivos, a avaliação de como esse se inicia e se propaga num dado ambiente, na quantificação dos gases tóxicos gerados e na determinação da elevação da temperatura no meio sinistrado e demais compartimentos por onde o incêndio se propagou. Nesse contexto, uma ferramenta que tem suprido algumas dificuldades da análise experimental na área de segurança de incêndio são os softwares fundamentados nos conceitos da fluidodinâmica computacional (CFD - Computacional Fluid Dynamics).

No presente estudo, utilizou-se o FDS (Fire Dynamics Simulator), software amplamente utilizado no meio científico, para modelar o compartimento bem como suas características de interesse para a investigação da deflagração e propagação de um incêndio.

\section{Resultados e Discussão}

O compartimento analisado trata-se de uma sala prismática com janelas e porta fechadas, dimensões cartesianas $X=4,60 m, Y=4,4 m$ e $Z=2,90 m$; onde as paredes são compostas por placas de amianto, piso e teto são de concreto armado, e o elemento de queima foi uma divisória interna de MDP (Médium Density Particleboard) nas dimensões $X=0,04 m, Y=2,7 m$ e $\mathrm{Z}=1,2 \mathrm{~m}$.

Com dados concisos do material combustível, obteve-se resultados coerentes com a realidade dos edifícios típicos da UNICAMP, que em geral são constituídos de alvenaria e são mobiliados com elementos em MDP. De acordo com os resultados, após 50 segundos de simulação foi gerado uma cortina de fumaça com temperatura de $75^{\circ} \mathrm{C}$ a $2 \mathrm{~m}$ do piso. Para 170 segundos de simulação obteve-se uma massa de gás a $1,3 \mathrm{~m}$ altura de $90^{\circ} \mathrm{C}$, conforme figura 1 .

Devido principalmente a pequena geometria do ambiente, simulado em escala real, em menos de 1 minuto a sala já estava tomada pela fumaça e altas temperaturas. Nestas circunstâncias um ocupante do recinto já não apenas teria perdido sua visibilidade, como teria seu campo respiração tomado pelos gases da queima, e também estaria exposto a temperaturas acima de $44^{\circ} \mathrm{C}$, temperatura máxima permissível sem que haja danos à pele humana conforme literatura técnica. Desta forma, a depender de fatores como evacuação e ventilação, um pequeno incêndio pode se mostrar nocivo aos ocupantes de tal localidade.

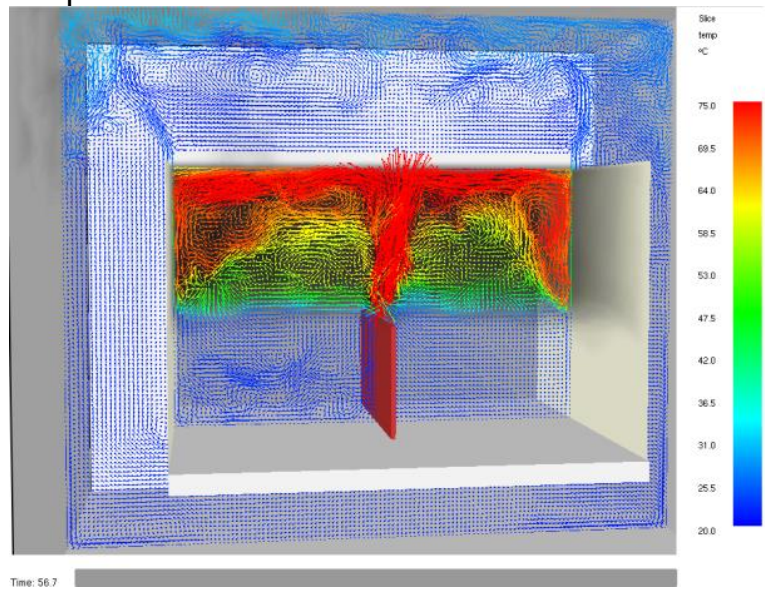

Figura 1. Simulação à 170s com alcances de temperatura de $90^{\circ} \mathrm{C}$.

\section{Conclusões}

A modelagem com base na fluidodinâmica computacional mostra-se uma ótima ferramenta para a etapa de anteprojeto colaborando com a avaliação do desempenho da edificação em situação de incêndio.

Embora não haja registros de deflagração de incêndios em edificações do campus da UNICAMP em Campinas, é interessante pensar na avaliação das condições de segurança contra incêndio das mesmas, uma vez que o incêndio é uma ação excepcional, de modo preventivo visando a seguridade dos ocupantes.

\section{Agradecimentos}

Agradeço primeiramente ao meu orientador, que sempre me apoiou em todo o caminhar da pesquisa, e ao CNPq instituição pela qual fui financiada.

\footnotetext{
${ }^{1}$ NCD Risk Factor Collaboration (NCD-RisC) elifescience.org 26 Julho 2016, 25 .

${ }^{2}$ Raia, R. Z.; Rosa, T. S.; Fonte, A. P. N.; Painéis de Madeira: Da MatériaPrima ao Acabamento, I SEAFLOR UFPR, 2017.

${ }^{3}$ Toleto, L. F.; Loureiro, F. S.; Problemas de Biotransferência de Calor: Simulações Numéricas de Queimadura de Pele XI SIMMEC / II EMMCOMP 28-30 Maio de 2014.
} 